\title{
2006-1703: DESIGN AND DEVELOPMENT OF VIRTUAL INSTRUMENT (VI) MODULES FOR ELECTRICAL POWER SYSTEMS COURSE
}

\section{Nikunja Swain, South Carolina State University}

Dr. Nikunja Swain is a Professor of Computer Science at South Carolina State University in Orangeburg, SC. He has over twenty five years of academic experience in teaching various computer sciences, information systems and engineering related graduate and undergraduate courses. He has published a number of articles (45+) in peer-refereed conferences and journals in the areas of Engineering, Management, and Computer Information Systems. He has procured research and development grants from the National Science Foundation (NSF), Department of Energy (DOE), Department of Defense (DOD), NASA, SC Department of Transportation (SC DOT), and he is a peer reviewer for American Society for Engineering Education (ASEE), Conference on Information Technology (CIT), Association for Computing Machinery (ACM), Computer Magazine, and International Journal of Applied Management and Technology (IJAMT). He has reviewed books on Information Systems, TCP/IP, Wireless Networks, and Microprocessors and he is a registered professional engineer in South Carolina. 


\title{
Design and Development of Virtual Instrument (VI) Modules For Electrical Power Systems Course
}

\begin{abstract}
The study of electrical power systems requires a good background on advanced mathematics and since most of the engineering technology programs don't require advanced mathematics, it is difficult to teach electrical power systems in these programs. A problem for electric power system students is the solution of problems in textbooks through the use of routine problem solving techniques such as equations and formulae. But the students' over reliance upon formulae and routine use of technique in problem solving too often lead to poor performance in real world scenarios. Also, the students' lack of comprehension of mathematical concepts results in time wastage during laboratory experiments, misinterpretations of lab data and underachievement in standardized science and engineering tests that stress the fundamentals. This problem can be effectively addressed by improving the student's conceptual understanding and comprehension of the topics through interactive learning and teaching with virtual instruments (VI) software package like LabVIEW.
\end{abstract}

This paper will discuss design and development of interactive instructional modules (VIs) for studying (a) Basic Three Phase and Single Phase Circuits, (b) Modeling of Transmission Lines, (c) Simple Economic Dispatch Problem and (d) steps to solve Load Flow problems through Newton Raphson Method.

\section{Introduction}

The engineering, science, and technology field at present is very dynamic. This is due to the recent advances in computer and other technologies. These advances are resulted in number of computer programs to solve traditional and novel problems. These programs use the computer's increased computational capabilities and assist in the design, development and control of complex systems in matter of minutes. Automation is becoming a part and parcel of every industry and industries need trained workforce to manage this new development. As a result, the engineering, technology, and science programs are under pressure to incorporate use of computers into their curriculum so that their graduates can be well trained in the use and application of these changing technologies and serve the needs of the industrial community. This is especially true for the electric power industry. Because of the recent advances in computer and other technologies, the complexity in all areas of the electrical power industry (generation, transmission, distribution, control, protection, reliability, economics, etc) has increased and the graduates of engineering and technology must be well trained to address the needs of the industry. To address this need, most of the engineering programs and some of the engineering technology programs have introduced courses, programs, and laboratories in power systems to 
provide the graduates with both the theoretical and practical knowledge and experience. The study of electrical power systems requires a good background on advanced mathematics and since most of the engineering technology programs don't require advanced mathematics, it is difficult to teach electrical power systems in these programs.

To address this issue, many software programs are currently used in academia to design and analyze different systems. Some of these programs are text driven where the students have to write number of lines of code to analyze and design systems. Sometimes these are not user friendly and take longer time. With the advent of Object-Oriented Programming, we have now programs that are interactive and user friendly. Students need not have to write codes and the system design and analysis is achieved from the schematics of the system. Some of the examples of such type programs are PSPICE from MicroSym Corporation and MatLab from MathWorks. This allows the student to spend less time in writing the code to solve the problem and to spend more time to understand the concepts. Approximately 10 to 15 years ago, National Instruments Corporation introduced a new program called LabVIEW. The acronym stands for Laboratory Virtual Instrumentation Engineering Work Bench. Originally designed for test and measurement applications, the program has been modified over the years to design and analyze various complex systems. LabVIEW is a graphical programming environment and is based on the concept of data flow programming. Data flow programming concept is different from the sequential nature of traditional programming languages, and it cuts down the design and development time of an application. It is widely accepted by industry, academia, and research laboratories around the world as a standard for data acquisition and instrument control software 1. Since LabVIEW is based on graphical programming, users can build instrumentation called "virtual instruments (VIs)" using software objects. With proper hardware these virtual instruments can be used for remote data acquisition, analysis, design and distributed control. The built-in library of LabVIEW has number of VIs that can be used to design and develop any system. LabVIEW can be used to address the needs of various courses in a technology and science curriculum ${ }^{2,3,4}$. The objective of this paper is to discuss the application of built-in VIs in LabVIEW to develop VI modules to be used in an introductory Electrical Power Systems Course.

This paper is arranged as follows: Section II discusses various LabVIEW application areas. Section III discusses the VI module for Basic Single Phase and Three Phase Circuits. Section IV discusses the VI module for Transmission Line Modeling. Section V discusses the VI module for Simple Economic Dispatch Problem. Section VI presents the discussion about load flow VI. Section VII presents the conclusion and discussion and Section VIII presents the references.

\section{LabVIEW Application Areas}

LabVIEW is extremely flexible and some of the application areas of LabVIEW $^{5}$ are Simulation, Data Acquisition \& Data Processing. The Data Processing library includes signal generation, digital signal processing (DSP), measurement, filters, windows, curve fitting, probability and statistics, linear algebra, numerical methods, instrument control, program development, control systems, and fuzzy logic. These features of LabVIEW, will help us in providing an Interdisciplinary Integrated Teaching and Learning experiences that integrates team-oriented, 
hands-on learning experiences throughout the engineering technology and sciences curriculum and engages students in the design and analysis process beginning with their first year.

LabVIEW can command DAQ boards to read analog input signals (A/D conversion), generate analog output signals (D/A conversion), read and write digital signals, and manipulate the onboard counters for frequency measurement, pulse generation, etc. The voltage data goes into the plug-in DAQ board in the computer, which sends data into computer memory for storage, processing, or other manipulation.

\section{Basic Single Phase and Three Phase VI Module}

The study of electric power system requires a good understanding of single phase and three phase circuits and courses in electric circuits and electric machines are usually the prerequisite courses, among others, are pre-requisites for the introductory power systems course. Almost every introductory electric power systems text provides a brief overview of electric circuits and the instructors spend one to two weeks of their lecture time reviewing electric circuits.

Depending upon the student demographics, the instructor may spend more time to discuss these topics. Use of programs to display waveforms of voltage, current, and power are very common in study of electric power systems as it enhances the instruction process and student comprehension. The VI modules presented below are developed to assist the faculty and student in this process and is used in the circuits and power systems course at South Carolina State University (SCSU) by this author.

\section{A. Power in Single-Phase AC Circuits ${ }^{6}$}

The equations used in this VI are the following:

$$
\begin{aligned}
& v(t)=V_{m} \cos \left(\omega t+\theta_{v}\right) \\
& i(t)=I_{m} \cos \left(\omega t+\theta_{i}\right) . \\
& p(t)=v(t) \times i(t) \ldots \ldots \ldots \ldots
\end{aligned}
$$

where $v(t)=$ instantaneous voltage, $V_{m}=$ maximum vale of the voltage, $\theta_{v}=$ angle of voltage in degrees, $i(t)=$ instantaneous voltage, $I_{m}=$ maximum vale of the voltage, $\theta_{i}=$ angle of current in degrees and $p(t)=$ instantaneous power.

Equation (3) can be further simplified to the following:

$$
\begin{aligned}
& p(t)=\left|V\left\|I\left|\cos \theta\left[1+\cos 2\left(\omega t+\theta_{v}\right)\right]+\right| V\right\| I\right| \sin \theta \sin 2\left(\omega t+\theta_{v}\right) \ldots \ldots .(4) \\
& p(t)=p_{R}(t)+p_{x}(t) \ldots \ldots \ldots \ldots \ldots \ldots \ldots \ldots \ldots \ldots \ldots . . .(5)
\end{aligned}
$$

where $p_{R}(t)=$ Energy flow into the circuit and $p_{x}(t)=$ Energy borrowed and returned by the circuit, $|V|=$ RMS value of voltage and $|I|=$ RMS value of current. 
The other equation that are used in this VI are equations to calculate the RMS values of voltage and current, the maximum value of current from voltage and impedance information, and the real power $(\mathrm{P})$, reactive power $(\mathrm{Q})$, and total power $(\mathrm{S})$.

$|V|=V_{m} / \sqrt{2} \cdots . .|I|=I_{m} / \sqrt{2} \ldots \ldots I_{m}=V_{m} \angle \theta_{v} / Z \angle \theta_{z}$

$P=|V||I| \cos \theta \ldots \ldots \ldots . Q=|V \| I| \sin \theta \ldots \ldots \ldots \ldots . . S=P+j Q \ldots \ldots$

$\theta=\theta_{v}-\theta_{i}$

The front panel of this VI consists of (a) the user inputs (controls) such as maximum voltage, angle of the voltage, impedance, angle of the impedance, starting value of the angle wt, final value of the angle wt, and increments and (b) the display (indicators) such as $\mathrm{P}, \mathrm{Q}, \mathrm{S}$, and graphs such as $v(t)$ and $i(t), p(t), p_{R}(t)$ and $p_{x}(t)$.

The heart of the diagram panel is the formula node that calculates and displays various quantities mentioned above. It also uses various arithmetic icons such as add, sub, divide, and multiply, and other icons to build arrays.

This VI was simulated with the input values from an example in ${ }^{6}$ and the results from the VI matched with the example results. The front panel of this VI is shown in Figure 1 (Figure 1A Circuit Diagram and User Input and Figure 1B - Output of the VI) and the diagram panel of this VI is shown in Figure 2 below:

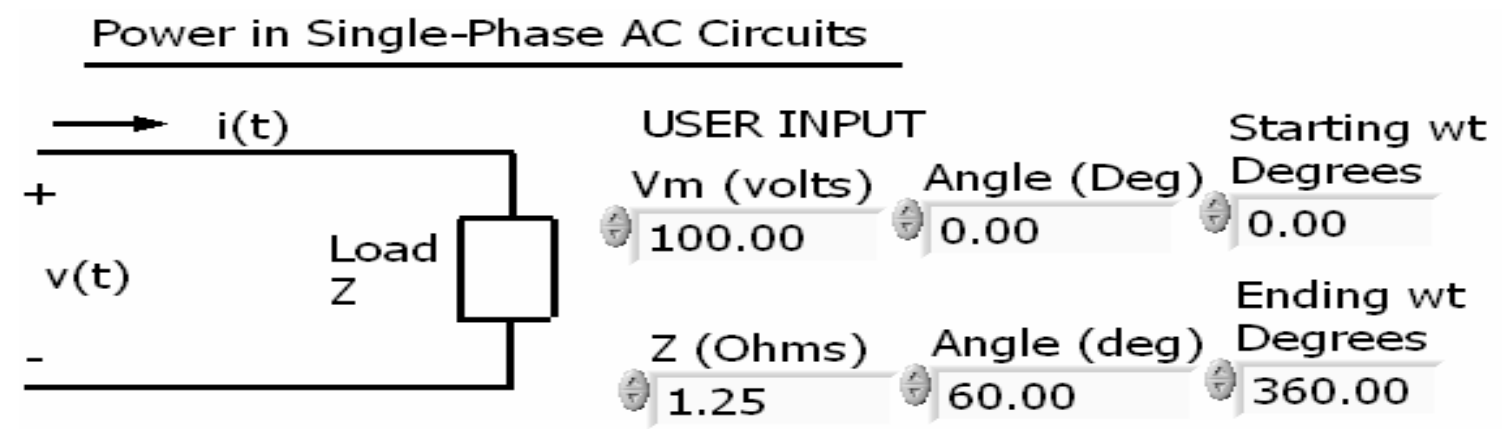

Figure 1 A - Circuit Diagram and User Input 


\section{OUTPUT}

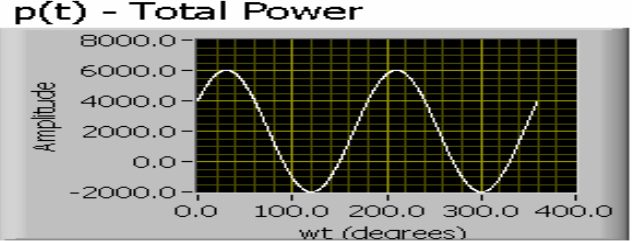

Plot of $v(t)$ and $i(t)$

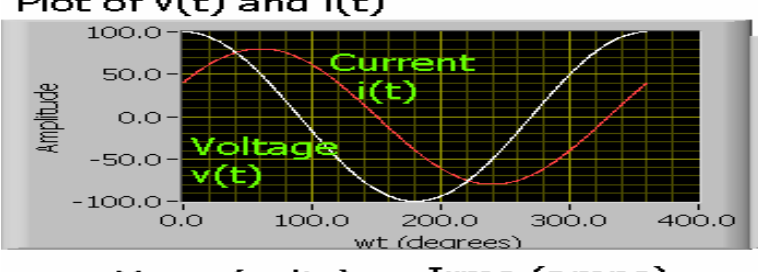

Vrms (volts)
0 6 70.7

Real Power (watts) - P

3) 0001.84
Irms (amps)

$0 \quad 56.5$

Reactive Power

(var) $-Q$

든 0463.04

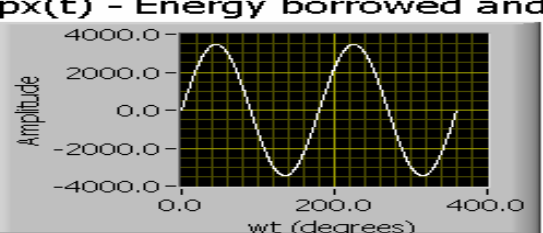

pr(t) - Energy flow into the circuit

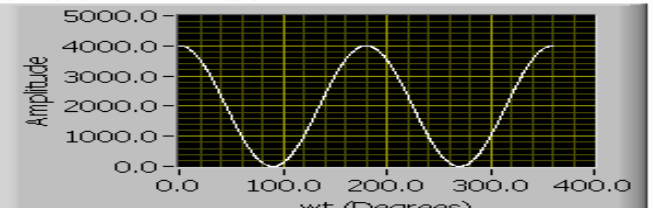

$p x(t)$ - Energy borrowed and returned

Total Power

(va) - S

o 4000.00

Figure 1B - VI Output

VI Diagram Panel

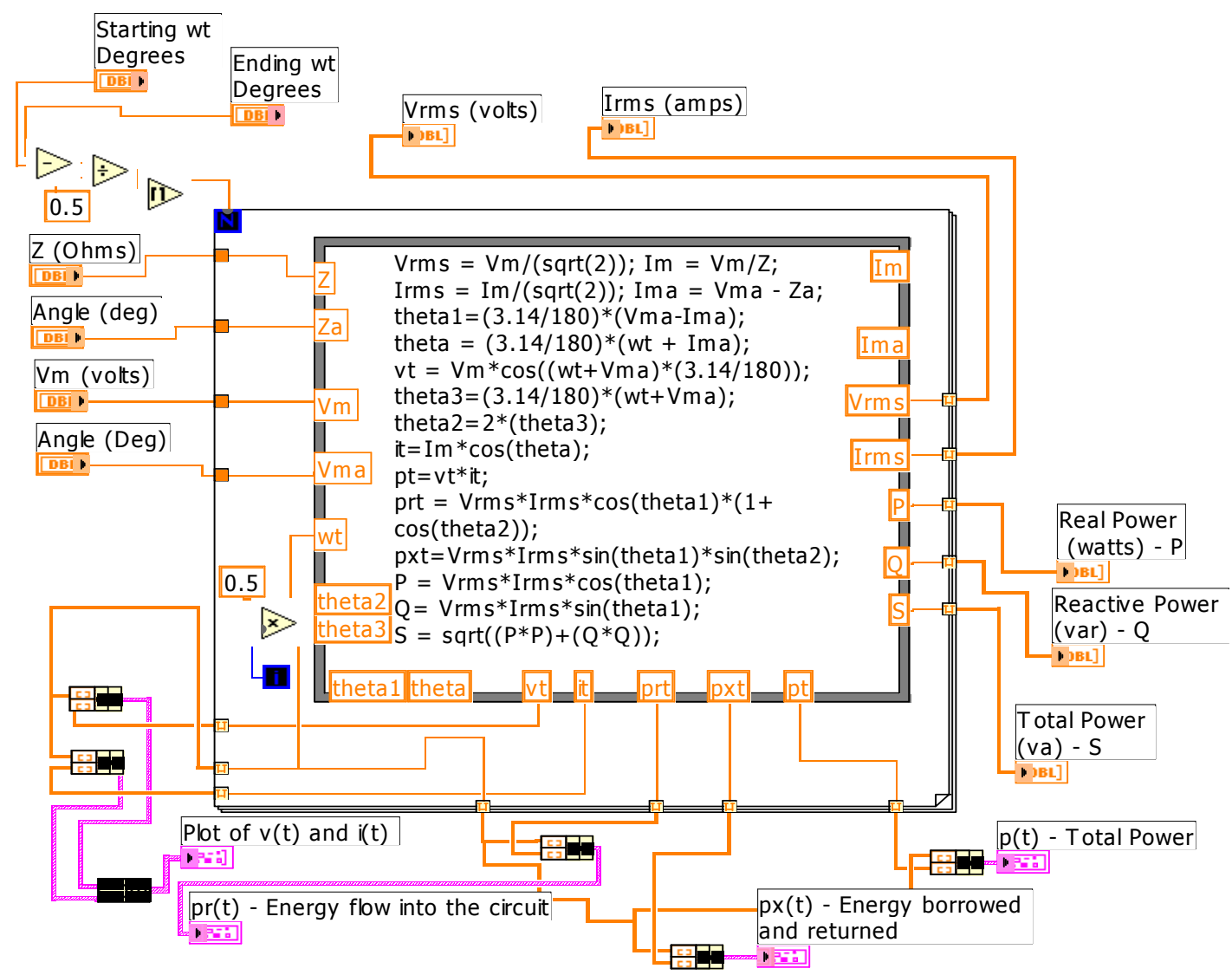

Figure 2 - VI Diagram Panel 


\section{B. Balanced Three Phase Circuits}

A VI was developed using the equations from ${ }^{6,7}$. These are standard three phase equations found in any electric circuits and/or electric power systems book. This VI simulated both the Delta and Star connection and calculated the line parameters and total power from the given phase parameters. The VI was simulated with input values from examples in ${ }^{6,7}$ and the results matched the example results. The front panel of this VI consisted of controls for user input of phase parameters and load information and indicators to display calculated parameters. The diagram panel simulated various equations through the use of built in arithmetic icons and other icons to deal with complex notations. It consisted of a case structure to decide between the type of connection (Star or Delta). The front panel of this VI indicating the simulation results of Star connection is shown in Figure 3 below.

VI Front Panel

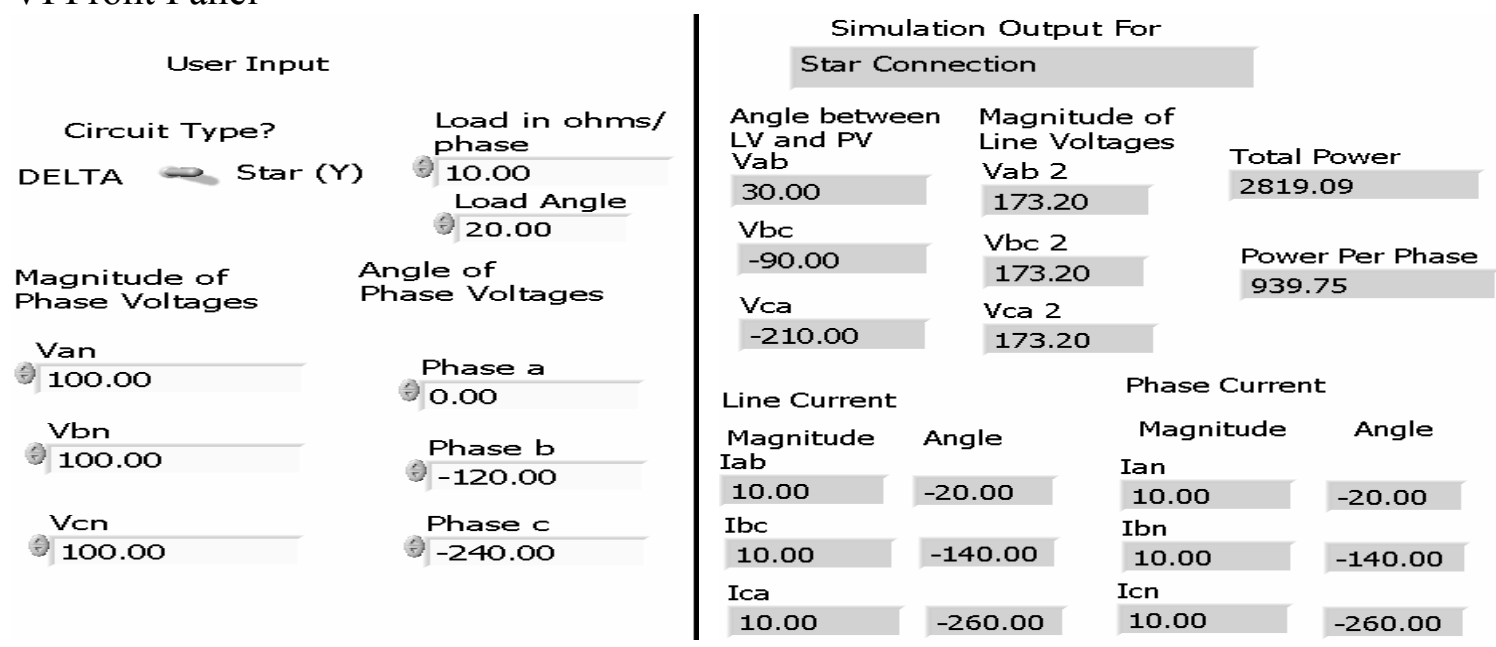

Figure 3 - Front panel of balanced three phase circuit VI

\section{VI to Model Transmission Line}

One of the requirements of the operation of any power systems is the maintenance of the voltage within specified limits at various points in the system ${ }^{7}$. This requires understanding the mathematical model of the transmission line and solution of various equations used to calculate voltage, current, and power at various points of a transmission line. The exact analysis of the transmission line involves a distributed parameter analysis as the parameters of the line (series capacitance, shunt capacitance, inductance, and resistance) are uniformly distributed over the length of the line. The exact analysis is complicated and time consuming. Fortunately, depending on the length of the line, some of these parameters can be lumped resulting in a simplified model with reasonably accurate results. 


\section{A. Short Transmission Line Model}

If the length of the line is less than or equal to 50 miles, then a Short Transmission Line model is used for analysis ${ }^{7}$. In This type of modeling, the capacitances have negligible effect and they are ignored. The resistances and inductances are lumped and represented by single units. The per-phase model of the line is basically a Series Circuit with a much simpler voltage, current and power equations. Figure 4 represents the diagram of such a line:

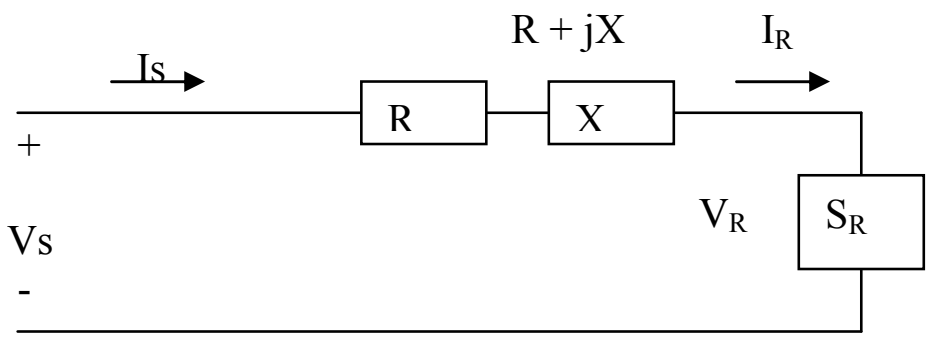

Figure 4 - Short Transmission Line Model

The line equations are as follows ${ }^{6}$ :

$$
\begin{aligned}
& Z=(r+j \omega L) l=R+j X \ldots(9) \ldots \ldots \ldots \ldots I_{R}=S_{R}{ }^{*}(3 \phi) / 3 V_{R} \ldots \ldots .(10) \\
& V_{s}=V_{R}+Z \times I_{R} \ldots \ldots \ldots \ldots \ldots . .(11) \ldots \ldots \ldots . . . I_{S}=I_{R} \\
& \% V R=\left(\left(\left|V_{R(N L)}\right|-\left|V_{R(F L)}\right|\right) /\left(\left|V_{R(F L)}\right|\right)\right) \times 100 \\
& S_{s(3 \phi)}=3 V_{s} I_{s}^{*} \ldots \ldots \ldots \ldots \ldots(14) \ldots \ldots . . . S_{L(3 \phi)}=S_{s(3 \phi)}-S_{R(3 \phi)} \ldots \\
& \eta=\left(P_{R(3 \phi)}\right) /\left(P_{s(3 \phi)}\right) \times 100
\end{aligned}
$$

Where $\mathrm{Z}=$ Impedance of the load, $\mathrm{I}_{\mathrm{R}}=$ Receiving end current, $\mathrm{V}_{\mathrm{s}}=$ Voltage at the sending end, $\mathrm{I}_{\mathrm{S}}$ $=$ current at the receiving end, $\% \mathrm{VR}=$ percentage voltage regulation, $\mathrm{S}_{\mathrm{S}(3 \Phi)}=$ sending end power $=\mathrm{P}_{\mathrm{s}}+\mathrm{j} \mathrm{Q}_{\mathrm{s}}, \mathrm{S}_{\mathrm{L}(3 \Phi)}=$ total line loss, and $\eta \dot{n}=$ Transmission line efficiency.

\section{A. $\quad$ Medium Transmission Line}

If the length of the line is greater than 50 miles and less than equal to 150 miles, then a Medium Transmission Line model is used for analysis ${ }^{7}$. In this type of modeling, the shunt admittance, usually pure capacitance is included in the calculations. If the total shunt capacitance is divided into equal parts placed at the sending end and receiving ends of the line, the circuit is called a nominal $\pi$. On the other hand if all of the shunt admittance of the line is lumped in the shunt arm of the $\mathrm{T}$ and the series impedance is divided equally between the two series arms results in the nominal T. The per-phase model of the line is basically a Series-Parallel Circuit with simpler voltage, current and power equations. Figure 5 represents the nominal $\pi$ model of such a line. 


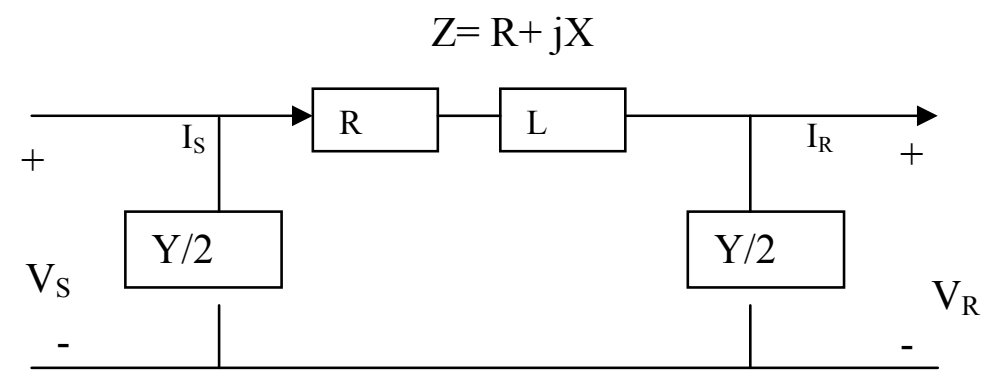

Figure 5 - Nominal $\pi$ model

The voltage and current equation of the nominal $\pi$ model is as follows ${ }^{7}$ :

$$
\begin{aligned}
& V_{s}=A V_{R}+B I_{R} \ldots \ldots .(17) \ldots \ldots \ldots I_{s}=C V_{R}+D I_{R} \ldots . .(18) \ldots \ldots \ldots A=D=Z Y / 2+1 \\
& B=Z \ldots \ldots \ldots \ldots \ldots(20) \ldots \ldots \ldots \ldots \ldots \ldots . C=Y\left(1+\frac{Z Y}{4}\right) \\
& \left.\% V R=\left(\left(\left|V_{s}\right| /|A|\right)-\left|V_{R(F L)}\right|\right) /\left(\left|V_{R(F L)}\right|\right)\right) \times 100
\end{aligned}
$$

The VI presented below simulated the mathematical equations for the Short and Medium Transmission line. This VI was simulated with the input values from a short transmission line example and a long transmission line example in ${ }^{6}$ and the results from the VI matched with the example results. The front panel for short transmission line simulation is shown in Figures 6

\begin{tabular}{|c|c|}
\hline $\begin{array}{l}\text { Length of } \\
\text { Line (Miles) }\end{array}$ & $\begin{array}{l}\text { Load Power Load Voltage } \\
\begin{array}{ll}\text { (MVA) } & (\mathrm{kV})\end{array}\end{array}$ \\
\hline 40.00 & 381.00 \\
\hline $\begin{array}{l}\text { Resistance } \\
\text { (ohms)/Mile }\end{array}$ & $\begin{array}{ll}\begin{array}{ll}\text { Inductance } & \text { Capacitance } \\
(\mathrm{mH}) / \text { Mile } & \text { (micro-f)/Mile }\end{array}\end{array}$ \\
\hline 0.15 & 1.3263 \\
\hline $\begin{array}{l}\text { Power Factor } \\
\text { (pf) }\end{array}$ & $\begin{array}{l}\text { Freq }(f) \\
\text { Lead }(\mathrm{Hz})\end{array}$ \\
\hline 0.80 & 60.00 \\
\hline
\end{tabular}
below.

Transmission Line Modeling

\begin{tabular}{|c|c|c|c|}
\hline \multicolumn{4}{|c|}{$799.8926-599.9194 i$} \\
\hline \multicolumn{4}{|c|}{ Voltage at Sending End (kV) } \\
\hline \multicolumn{4}{|c|}{$143.81+12.40 \mathrm{i}$} \\
\hline Mag & \multicolumn{3}{|c|}{ Angle Vsending (L-L) } \\
\hline 144 & \multicolumn{3}{|c|}{$4.93 \quad 250.01$} \\
\hline \multicolumn{4}{|c|}{ Power at Sending End (MVA) } \\
\hline \multicolumn{4}{|c|}{$322.80+288.58 i$} \\
\hline \multicolumn{4}{|c|}{ Magnitude Angle 2} \\
\hline 322.80 & 41.80 & & \\
\hline \multicolumn{4}{|c|}{ Voltage Regulation (\%) Efficiency (\%) } \\
\hline \multicolumn{4}{|c|}{13.64} \\
\hline \multicolumn{4}{|c|}{ A Parameter } \\
\hline \multicolumn{4}{|c|}{$0.9983+0.0005 i$} \\
\hline \multicolumn{4}{|c|}{ C Parameter } \\
\hline \multicolumn{4}{|c|}{$0.0000+0.0002 i$} \\
\hline
\end{tabular}

$$
\begin{aligned}
& \text { Series Impedance Magnitude Angle } \\
& \text { Per Phase (Ohms) (Ohms) } \\
& 6.0000+20.000120 .88 \\
& \text { Degrees } \\
& 73.30
\end{aligned}
$$

Current At Receiving End (Amp)

Figure 6 - Front panel of short transmission line simulation VI 
V. Economic Dispatch (distribution of load between units in a plant) ${ }^{7}$

Economic Dispatch is an important area of study in a power systems course as it deals with practices to achieve maximum efficiency of operation. This in turn helps to maintain a reasonable relation between cost to a consumer and the cost to the company delivering the power in the face of constantly rising prices for fuel, labor, supplies, and maintenance. The Economic Dispatch study provide solutions for operating the system for any load condition with a minimum cost for delivered power and determines the contribution from each plant and from each unit within a plant. Economic Dispatch is a complex topic and covers topics such as distribution of load between plants, transmission loss as a function of plant generation, distribution of load between plants, penalty factors and loss coefficients, and automatic generation control. Understanding of the topics requires knowledge in load flow, parameter optimization with inequality constraints and higher level calculus.

The simplest economic dispatch problem is the case when transmission line losses are neglected. The model doesn't consider system configuration and line impedances. In essence, the model assumes that the system is only one bus with all generation and loads connected to it.

The Economic Dispatch problem dealing with the distribution of loads between units in a plant uses the incremental fuel cost methodology. If $\mathrm{Fn}=$ input to unit $\mathrm{n}$, dollars per hour, Pn = output of unit $\mathrm{n}, \mathrm{MW}$, then $\mathrm{dFn} / \mathrm{dPn}$ is the incremental fuel cost of the unit in dollars per megawatthour.

The Economic Dispatch VI presented in this paper uses the incremental fuel cost methodology for allocating load between two units. It simulates an example in ${ }^{7}$ successfully. The VI can be extended to handle more than two units. The incremental fuel costs are:

$$
d F 1 / d P 1=0.0080 P 1+8.0 \ldots . \text { and } d F 2 / d P 2=0.0096 P 2+6.4
$$

Both the units are operating at all times and the total load varies from 250 to $1250 \mathrm{MW}$. The maximum and minimum loads on each unit are 625 and $100 \mathrm{MW}$, respectively. The objective is to determine the allocation of loads and plant incremental fuel factor.

The incremental fuel cost is calculated at minimum load. The unit having the minimum incremental fuel cost, supplies the additional load until its incremental fuel cost becomes equal to the other unit. After that the load distribution is solved assuming equal incremental fuel cost for both units. The simulation results clearly indicate that.

The front panel of this VI is shown Figures 7A through 7G below. 


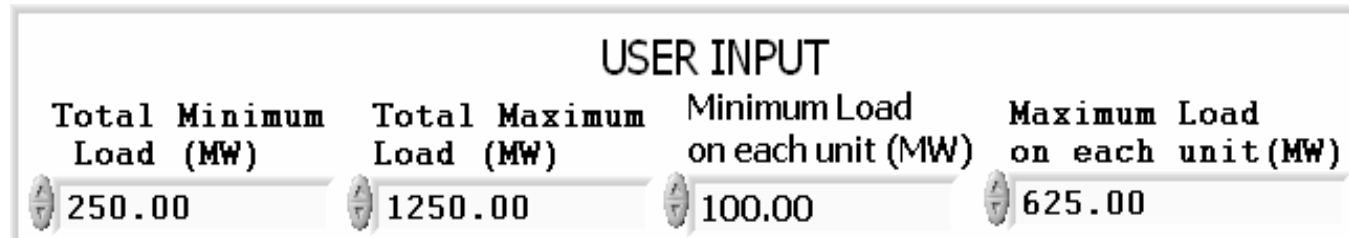

Figure 7A - VI Front panel depicting user input

\begin{tabular}{|c|c|c|}
\hline \multicolumn{3}{|c|}{ VI Output - Unit Incremental Fuel cost at total minimum load } \\
\hline $\begin{array}{l}\text { Incremental Fuel } \\
\text { Cost Unit1 (U1) (\$) } \\
\text { at Minimum Load (MW) }\end{array}$ & $\begin{array}{l}\text { Incremental Fuel } \\
\text { Cost Unit } 2(\mathrm{U} 2)(\$) \\
\text { ) at Minimum Load (MW) }\end{array}$ & Total Minimum Load (MW) \\
\hline 8.80 & 7.36 & 200.00 \\
\hline
\end{tabular}

Figure 7B - VI output depicting unit incremental fuel cost at minimum load

Distribution of load between units for Plant Output of $250 \mathrm{MW}$

\begin{tabular}{lll} 
Unit1 (MW) & Unit2 (MW) & $\begin{array}{l}\text { Plant Incremental } \\
\text { Factor (\$) }\end{array}$ \\
\hline 100.00 & 150.00 & 7.84 \\
\hline
\end{tabular}

Remarks

Since Incremental Cost of Unit 1 is greater than the incremental cost of Unit 2, Additional Load comes from Unit 2, until the incremental cost of Unit2. is equal to incremental cost of Unit 1

Figure 7C - VI output for distribution of load for plant output of $250 \mathrm{MW}$

\begin{tabular}{|c|c|c|}
\hline \multirow[b]{2}{*}{$\begin{array}{l}\text { Incrementa Fuel } \\
\text { Cost Unit1 (U1) ( } \$ \text { ) } \\
\text { at MaximLm Load (MV) }\end{array}$} & $\begin{array}{l}\text { jon of incremental fuel cos } \\
\text { unit at maximum load }\end{array}$ & \\
\hline & $\begin{array}{l}\text { Incremental Fuel } \\
\text { Cost Unit2 (U2) (\$) } \\
\text { at Maximum Load (MW) }\end{array}$ & $\begin{array}{l}\text { Total Maximum } \\
\text { Load (MW) }\end{array}$ \\
\hline 13.00 & 12.40 & 1250.00 \\
\hline
\end{tabular}

Distribution of load for Plant Output $=1250 \mathrm{MW}$

$\begin{array}{lll}\text { Unit1 (MW) Unit2 (MW) } \\ 625.00 & 625.00 & \text { Remarks }\end{array}$

Plant Incremental

Factor (\$)

13.00

Since incremental cost of Unit1 is greater than the incremental cost of Unit2, additional load comes from Unit 2 until the incremental costs are equal.

Figure 7D - VI output for distribution of load for plant output of $1250 \mathrm{MW}$ 


\begin{tabular}{|l|}
\hline 7.84 \\
\hline 8.36 \\
\hline 8.87 \\
\hline 9.39 \\
\hline 9.90 \\
\hline 10.42 \\
\hline 10.94 \\
\hline 11.45 \\
\hline 11.97 \\
\hline 12.48 \\
\hline 13.00 \\
\hline 0.00 \\
\hline
\end{tabular}

Load distribution as a factor of plant incremental factor - Results from VI

Figure 7E - Distribution of load as a factor of plant incremental factor

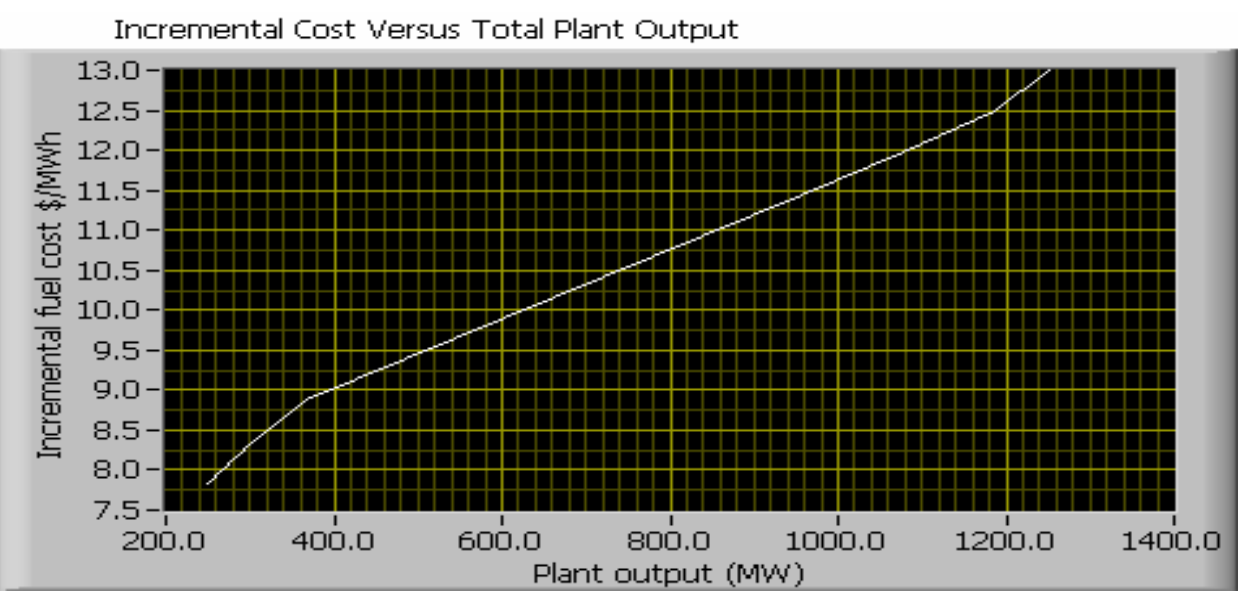

Figure 7F - Plot of incremental fuel cost versus total plant output

Plant output versus output of each unit

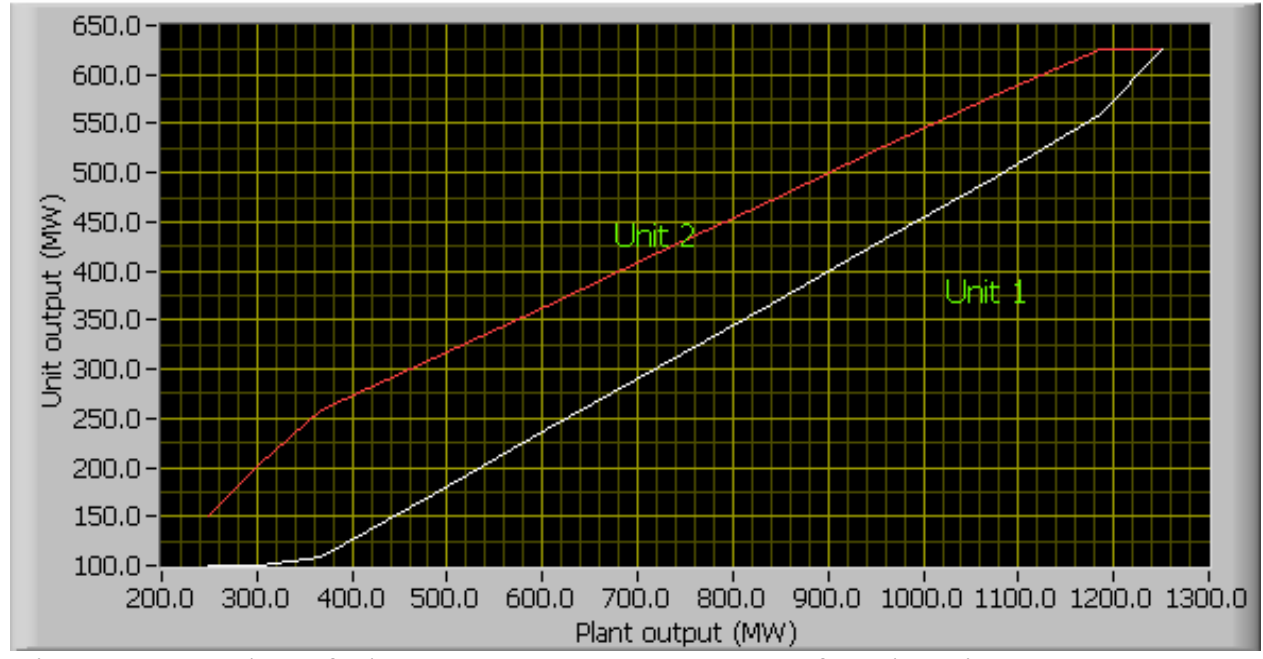

Figure $7 \mathrm{G}-$ Plot of plant output versus output of each unit 


\section{Load Flow Analysis VI}

The Load Flow VI is currently being developed. The author plans to use the following steps to design and develop this $\mathrm{VI}^{6,7,8}$ :

1. Represent the system by its one line diagram.

2. Convert all quantities to Per Unit.

3. Draw the Impedance Diagram

4. Obtain the Ybus matrix.

5. Classify the buses

6. Determine the missing variables, by assumptions (unless it is specified)

7. Find approximations for the given Real and Reactive Power using the assumed and given values for voltage/angles/admittance.

8. Write the Jacobian Matrix for the first iteration of the Newton Raphson Method.

9. Solve for the unknown differences, using Cramer's Rule.

10. Repeat step $7-9$ iteratively until the unknown differences approaches zero.

VII. Conclusion and Discussion

The VI modules presented in this paper are tested with the input values from various examples in textbooks and results matched with the results of the examples. This author has developed number of other VIs for other courses and used them as needed. The modules presented in this paper are used in circuits and power systems course. A number of software packages are currently being used in engineering, technology, and sciences curriculum. While some of them require programming background, others are designed for specific course requirements. LabVIEW has features and built in virtual instrument modules identical to most of the features found in all these software packages. MATLAB is extensively used for studying Circuits and Power Systems and number of books and literature available on this topic. It requires writing codes. LabVIEW on the other hand, provides a graphical environment to solve complex problems. No or minimal programming knowledge is necessary to design and develop the VI modules. LabVIEW has provision to transfer data between LabVIEW and MATLAB and call MATLAB from the LabVIEW environment. Therefore, one can use LabVIEW only to address the needs of various courses. This will be beneficial for students and faculty and introduce standardization across the curriculum.

The modules presented in this paper are developed using simplified models. Although this is sufficient for introducing the concepts, elaborate models must be incorporated into the modules to address the complex real world situations. The author plans to address these by incorporating the following provisions in future:

1. Delta-Star conversion analysis VI.

2. Long transmission Line Model VI.

3. Modify the existing Economic Dispatch VI to address second order incremental fuel cost equation.

4. Add a VI that addresses line losses and other economic dispatch issues. 
5. Add load flow VIs.

6. Design and develop a toolkit with all these VIs and made it available to others.

\section{References}

1. Chugani, M., Samant, A., and Cerna, N. LabVIEW Signal Processing, Prentice Hall, NJ 07458, 1998.

2. Anderson, J. A., Korrapati. R. B., \& Swain. N. K., "Digital signal processing using virtual instrumentation". Proceedings of SPIE Vol. 4052.

3. Korrapati, R. B. \& Swain. N. K., "Study of Modulation using Virtual Instruments". Proceedings of National Conference on Allied Academies, Spring 2000.

4. Swain, N. K., Anderson, J. A., \& Korrapati. R. B. "Computer based virtual engineering Laboratory (CBVEL) and Engineering Technology Education". 2000 Annual ASEE Conference Proceedings.

5. Lisa Wells and Jeferey Travis, LabVIEW for Everyone, Graphical Programming Even Made Easier, Prentice Hall, NJ 07458, 1997.

6. Saadat, Hadi, Power Systems Analysis, Prentice Hall, NJ, 1999.

7. Stevenson, William D. Elements of Power System Analysis, McGraw-Hill, NY, 1982.

8. "Steps to solve power flow analysis; for dummies", retrieved on January 17, 2006 from http://www.ece.uwaterloo.ca/ ece261/pfe.pdf 